University of Nebraska - Lincoln

DigitalCommons@University of Nebraska - Lincoln

June 2006

\title{
Mammalian and other eukaryotic selenocysteine tRNAs
}

\author{
Bradley A. Carlson \\ National Cancer Institute, National Institutes of Health, Bethesda, MD \\ Xue-Ming Xu \\ National Cancer Institute, National Institutes of Health, Bethesda, MD \\ Rajeev Shrimali \\ National Cancer Institute, National Institutes of Health, Bethesda, MD \\ Aniruddha Sengupta \\ National Cancer Institute, National Institutes of Health, Bethesda, MD \\ Min-Hyuk Yoo \\ National Cancer Institute, National Institutes of Health, Bethesda, MD
}

See next page for additional authors

Follow this and additional works at: https://digitalcommons.unl.edu/biochemgladyshev

Part of the Biochemistry, Biophysics, and Structural Biology Commons

Carlson, Bradley A.; Xu, Xue-Ming; Shrimali, Rajeev; Sengupta, Aniruddha; Yoo, Min-Hyuk; Irons, Robert; Zhong, Nianxin; Hatfield, Dolph L.; Lee, Byeong Jae; Lobanov, Alexei V.; and Gladyshev, Vadim N., "Mammalian and other eukaryotic selenocysteine tRNAs" (2006). Vadim Gladyshev Publications. 42. https://digitalcommons.unl.edu/biochemgladyshev/42

This Article is brought to you for free and open access by the Biochemistry, Department of at DigitalCommons@University of Nebraska - Lincoln. It has been accepted for inclusion in Vadim Gladyshev Publications by an authorized administrator of DigitalCommons@University of Nebraska - Lincoln. 


\section{Authors}

Bradley A. Carlson, Xue-Ming Xu, Rajeev Shrimali, Aniruddha Sengupta, Min-Hyuk Yoo, Robert Irons, Nianxin Zhong, Dolph L. Hatfield, Byeong Jae Lee, Alexei V. Lobanov, and Vadim N. Gladyshev 


\title{
SELENIUM \\ Its Molecular Biology and Role in Human Health, Second Edition
}

Edited by

\author{
Dolph L. Hatfield \\ National Cancer Institute, USA \\ Marla J. Berry \\ University of Hawaii, USA \\ and \\ Vadim N. Gladyshev \\ University of Nebraska, USA
}

黛 ${ }_{2006}^{\text {Springer }}$ 


\section{Chapter 3. Mammalian and other eukaryotic selenocysteine tRNAs}

Bradley A. Carlson, Xue-Ming Xu, Rajeev Shrimali, Aniruddha Sengupta, Min-Hyuk Yoo, Robert Irons ${ }^{1}$, Nianxin Zhong and Dolph L. Hatfield

Molecular Biology of Selenium Section, Laboratory of Cancer Prevention, Center for Cancer Research, National Cancer Institute, National Institutes of Health, Bethesda, MD 20892,USA

Byeong Jae Lee

Laboratory of Molecular Genetics, Institute of Molecular Biology and Genetics, School of Biological Sciences, Seoul National University, Seoul 151-742, Korea

Alexey V. Lobanov and Vadim N. Gladyshev

Department of Biochemistry, University of Nebraska, Lincoln, NE 68688, USA

Summary: Selenocysteine (Sec) tRNA occupies a prominent position in the expression of selenoproteins as it is essential for their synthesis and it provides the means by which selenium is co-translationally inserted into protein as the amino acid, Sec. Thus, Sec tRNA is regarded as the principle constituent in selenoprotein synthesis. Many features unique to this tRNA have been characterized over the years in mammals and other eukaryotes. In the last five years, the major advances have been in an elucidation of the different roles that the two major Sec tRNA isoforms play in selenoprotein biosynthesis and in Sec biosynthesis. One isoform appears to be responsible for the synthesis of selenoproteins that have roles in housekeeping functions and are less dependent on selenium status for their expression. The second isoform, that differs by only a single methyl group at the 2'- $O$-hydroxylribosyl moiety at position 34 (designated Um34), appears to be responsible for the expression of selenoproteins that have roles in stress-related phenomena and are highly dependent on selenium for their expression. Several new observations regarding Sec biosynthesis, which occurs on its tRNA, have also been recently made. Other recent advances involving Sec tRNA have used this molecule as a tool for determining whether eukaryotes outside the animal kingdom contain the machinery dedicated for the insertion of Sec into protein. These recent findings are discussed in this chapter.

${ }^{T} \mathrm{RI}$ is also affiliated with the Nutritional Science Research Group, Division of Cancer Prevention, National Cancer Institute, National Institutes of Health, Bethesda, MD 20892. 


\section{Introduction}

Of all the tRNAs that have been identified and whose functions have been characterized, selenocysteine (Sec) tRNA is arguably the most fascinating. For example, it is responsible for the translation of an entire class of proteins, the selenoproteins. Unlike the other 20 amino acids in protein, $\mathrm{Sec}$ is biosynthesized on its tRNA. Furthermore, while the other 20 aminoacyltRNAs share a common elongation factor, eEF-2, Sec-tRNA has its own dedicated elongation factor, EFsec [1,2]. In addition, there are many other novel features in its primary and secondary structures, as well as in its transcriptional properties, which are unique only to this tRNA. As these unique characteristics have been reviewed in detail recently [3], they will not be further discussed herein. Of importance to our present discussion on Sec tRNA in mammals is that it exists as two isoforms that differ from each other by a single methyl group, 2'- $O$-methylribose, which is present at position 34 , the wobble position of the anticodon. This methyl group is designated Um34 and its synthesis is a highly specialized event in the maturation of Sec tRNA (see below).

Sec tRNA has been detected in prokaryotes, eukaryotes and archaea, and therefore, is widespread in nature. However, while Sec tRNA has been characterized extensively in mammals and other animals [3], little is known about the properties, functions and distribution of this tRNA in other eukaryotic organisms. In fact, Sec tRNA, selenoproteins and/or the Sec protein insertion machinery have been reported thus far in only a handful of eukaryotes other than animals. The new data on the roles of the two mammalian isoforms in selenoprotein biosynthesis, Sec synthesis on its tRNA in mammalian cells and the occurrence of Sec tRNA in eukaryotes outside the animal kingdom are subjects of this review. For further information, the reader is referred to other, more extensive reviews on this subject $[3,4]$.

\section{Um34, a highly specialized event in mammalian Sec tRNA ${ }^{[S e r] S e c}$}

Sec tRNA is designated as Sec tRNA ${ }^{[\text {Ser]Sec }}$, since it is first aminoacylated with serine and the biosynthesis of Sec occurs on the tRNA [3]. As noted above, there are two isoforms of Sec tRNA ${ }^{[\operatorname{Ser}] S e c}$ that differ from each other by the presence of Um34. Both isoforms have a highly modified base at position 34,5 -methoxycarbonylmethyluridine $\left(\mathrm{mcm}^{5} \mathrm{U}\right)$, and they are thus designated $\mathrm{mcm}^{5} \mathrm{U}$ and $\mathrm{mcm}^{5} \mathrm{Um}$. The synthesis of $\mathrm{Um} 34$, which is the last step in the maturation of Sec tRNA ${ }^{[\mathrm{Ser}] \mathrm{Sec}}$, has been described as a highly specialized event [3] since its addition 1) is dependent on the primary and tertiary structure of Sec tRNA ${ }^{[\mathrm{Ser}] \mathrm{Sec}}$, including the prior synthesis of all modified bases (the synthesis of other modified bases is not nearly as stringently dependent on these factors) [5], 2) is dependent upon selenium status [4], 3) alters secondary and tertiary structure [6], and 4) is responsible 
for the synthesis of a subset of selenoproteins implicated in stress response $[7,8]$. The stress-related selenoproteins include glutathione peroxidase- 1 and 3, SelR, SelT and likely SelW, and the dependence of this subclass of selenoproteins on $\mathrm{mcm}^{5} \mathrm{Um}$ is discussed in greater detail in Chapter 29 (see also $[7,8])$.

Interestingly, the expressions of stress-related selenoproteins, like the occurrence of $\mathrm{mcm}^{5} \mathrm{Um}$, are dependent on selenium status. The lack of expression of this subclass of selenoproteins is a translational event due to the lack of Um34 on $\mathrm{mcm}^{5} \mathrm{Um}$ as the amount of mRNA encoding some of these selenoproteins is more than adequate for their expression following the reduction of $\mathrm{mcm}^{5} \mathrm{Um}$ due to selenium deficiency. However, the level of mRNA encoding some of these selenoproteins, e.g., GPxl and SelW, is substantially reduced during selenium deficiency. This dependence of selenoprotein mRNA expression on selenium status was proposed to result from the mechanism of nonsense mediated decay (NMD), wherein the UGA $\mathrm{Sec}$ codon in selenoprotein genes is recognized as nonsense $[9,10]$. Different selenoprotein mRNAs manifest varying degrees of sensitivity to NMD and the reason for this is not clearly understood. In this regard, the sensitivity of $\mathrm{mcm}^{5} \mathrm{Um}$ to selenium status is of particular interest since the overall levels of the Sec tRNA ${ }^{[\mathrm{Ser}] \mathrm{Sec}}$ population decrease significantly under conditions of selenium deficiency, while the amounts of $\mathrm{mcm}^{5} \mathrm{U}$ remain largely unchanged and may even be enriched (described in detail in [3]). A possible sequence of events during selenium deficiency is that Um34 synthesis is reduced which in turn prevents the expression of several stress-related selenoproteins and the corresponding mRNAs manifest varying degrees of sensitivity to NMD.

The dependence of a subclass of proteins, and in this case, stress-related selenoproteins, on a methyl group for recoding a nonsense codon (UGA) to generate their expression is, to our knowledge, an unprecedented observation in translation. To elucidate the means by which $\mathrm{Um} 34$ is responsible for the expression of a subset of selenoproteins, we examined various parameters of selenoprotein mRNAs such as nucleotide context of the UGA codon, position of the UGA codon in the open reading frame and the class of the Sec insertion sequence element (located in the 3' untranslated region of selenoprotein $\mathrm{mRNAs}$ and required for the incorporation of Sec into protein [11]), but none of these features revealed any clear pattern that would explain this phenomenon (reviewed in [3]). The precise mechanism of how UGA is recoded by $\mathrm{mcm}^{5} \mathrm{Um}$ in stress-related selenoprotein mRNAs resulting in their expression is currently under investigation.

\section{Um34 methylase}

Although the methylase that synthesizes Um34 on Sec tRNA ${ }^{[\mathrm{Ser}] \mathrm{Sec}}$ has not been identified, a protein described by Ding and Grabowski, designated SECp43 [12], may have a role in Um34 synthesis [13]. These investigators 
reported that SECp43 existed in a complex with a $48 \mathrm{kDa}$ protein and $\mathrm{Sec}$ $\mathrm{tRNA}^{[\mathrm{Ser}] \mathrm{Sec}}$ in HeLa cell extracts. A $48 \mathrm{kDa}$ protein, designated soluble liver antigen (SLA), had been earlier characterized as it co-precipitated with Sec tRNA $^{[\operatorname{Ser}] \operatorname{Sec}}$ after being targeted by antibodies in patients with an autoimmune chronic hepatitis [14]. We recently found that the $48 \mathrm{kDa}$ protein which formed a complex with SECp43 and Sec tRNA ${ }^{[\operatorname{Ser}] \operatorname{Sec}}$ is indeed SLA $[13,15]$. Furthermore, we found that knockdown of SECp43 in mammalian cells using RNAi technology reduced the formation of Um34 [13] suggesting that it is involved in Um34 synthesis. Further studies are required to determine if SECp43 is associated with methylase function and how it is precisely involved in Um34 synthesis. However, we investigated additional parameters of SECp43 and SLA [13]. The targeted removal of either SECp43 or SLA affected the binding of the other to Sec tRNA ${ }^{[\mathrm{Ser}] \mathrm{Sec}}$, even though tRNA ${ }^{[\mathrm{Ser}] \mathrm{Sec}}$ attachment was most affected when SLA was the targeted member of the complex. In addition, we observed that SECp43 is located primarily in the nucleus, while SLA occurs in the cytoplasm. Cotransfection of both proteins resulted in the nuclear translocation of SLA. This result suggested that SECp43 may also serve as a chaperone for shuttling SLA and Sec tRNA ${ }^{\text {[Ser]Sec }}$ between different cellular compartments. SLA likely has a role in the biosynthesis of Sec as discussed below.

\section{Sec Biosynthesis}

Sec is distinctive from the other 20 amino acids in protein in that Sec biosynthesis occurs on its tRNA [3,5]. Although asparagine, glutamine and cysteine biosynthesis can occur on tRNA ${ }^{\text {Asn }}$, $\operatorname{tRNA}^{\mathrm{Gln}}$ [16] and tRNA ${ }^{\text {Cys }}$ [17], respectively, this means of synthesizing these amino acids appears to be restricted to only a few life forms. However, Sec apparently is synthesized on its tRNA in all organisms that encode the Sec-protein insertion machinery which, as noted above, is widespread in nature. Serine is attached to Sec $\mathrm{tRNA}^{[\mathrm{Ser}] \mathrm{Sec}}$ by seryl-tRNA synthetase, and thus, the identity elements for recognizing this tRNA are for serine and not Sec. The identity elements in Sec tRNA ${ }^{[\operatorname{Ser}] S e c}$ are located in the discriminator base and the long extra arm which are essential to its aminoacylation, even though the acceptor, $\mathrm{T} \psi \mathrm{C}$ and D stems also have roles in the identity process (reviewed in [3,5]). Following the aminoacylation of $\operatorname{Sec} t \mathrm{RNA}^{[\mathrm{Ser}] \mathrm{Sec}}$, the serine moiety serves as the backbone for the synthesis of Sec on its tRNA.

The enzyme that carries out the synthesis of Sec utilizing the serine moiety on seryl-tRNA ${ }^{[\mathrm{Ser}] \mathrm{Sec}}$ is designated Sec synthase and its identity and mechanism of action has been thoroughly characterized in bacteria (Chapter 2). However, in mammals, a homolog of the bacterial enzyme is absent and the overall biosynthesis of Sec on its tRNA has not been established. In 1970 , a kinase activity that phosphorylated a minor species of seryl-tRNA to form phosphoseryl-tRNA was observed in rooster liver [18] and a minor 
seryl-tRNA that decoded UGA was reported in bovine, rabbit and chicken livers [19]. The phosphoseryl-tRNA and the seryl-tRNA that decoded UGA were subsequently found to be $\operatorname{Sec} t R N A^{[\operatorname{Ser}] \operatorname{Sec}}[20]$, but the kinase activity remained elusive until only recently. A gene for mammalian phosphoseryl$\mathrm{tRNA}^{[\mathrm{Ser}] \mathrm{Sec}}$ kinase (pstk) was identified using a comparative genomics approach by searching completely sequenced archaeal genomes for a kinaselike protein with the pattern of occurrence similar to that of known components of the Sec insertion machinery [21]. A gene corresponding to a potential mouse pstk was cloned, the gene product (PSTK) expressed and characterized. PSTK specifically phosphorylated the seryl moiety on seryl$\mathrm{tRNA}^{[\mathrm{Ser}] \mathrm{Sec}}$ confirming that indeed the seryl-tRNA ${ }^{[\mathrm{Ser}] \mathrm{Sec}}$ kinase had been correctly identified. A search of proteins with homology to mammalian PSTK revealed homologs in Drosophila, Caenorhabditis elegans, Methanopyrus kandleri and Methanococcus jannaschii. These observations suggest that the function of PSTK has been conserved in archaea and eukaryotes that synthesize selenoproteins, but this function is absent in bacteria and eukaryotes, e.g., plants and yeast, that do not synthesize selenoproteins.

Since PSTK has been highly conserved in evolution, it must have an important role in selenoprotein biosynthesis and/or its regulation [21,22]. A similar reaction as that which may occur in Sec biosynthesis in mammals has been observed in archaea wherein cysteine biosynthesis on $\mathrm{tRNA}^{\text {Cys }}$ takes place by the initial aminoacylation of the tRNA with phosphoserine and subsequently converting the phosphoserine moiety to cysteine by a pyridoxal phosphate-containing Cys synthase [17]. This pathway serves as an excellent model providing further evidence that phosphoseryl-tRNA ${ }^{[\mathrm{Ser}] \mathrm{Sec}}$ is indeed an intermediate in the biosynthesis of Sec (see also [22]).

A mammalian Sec synthase distinct from that described in bacteria (Chapter 2) could then act upon phosphoseryl-tRNA ${ }^{[\operatorname{Ser}] \operatorname{Sec}}$ in removing the phosphate group and accepting the active selenium donor to make selenocysteyl-tRNA ${ }^{[\operatorname{Ser}] \operatorname{Sec}}$. Interestingly, a candidate Sec synthase is SLA (see above for further characterization of SLA). This protein was identified several years ago [14], and has more recently been characterized as an important member of the Sec biosynthesis and protein insertion machinery $[13,15]$ (see also Chapter 8).

The active form of selenium that is donated to the intermediate in the biosynthesis of $\mathrm{Sec}$ has been characterized in bacteria as monoselenophosphate, which is synthesized from selenide and ATP by selenophosphate synthetase [23]. Although the active selenium donor has not been characterized in eukaryotes, two selenophosphate synthetase genes, designated Sps 1 and Sps2, have been detected in mammals [24-26]. SPS2, the gene product of Sps2, is a selenoprotein which suggests that it may be involved in the autoregulation of its own biosynthesis [24]. When the 
activated form of selenium is donated to the intermediate, which might be a product of phosphoseryl-tRNA ${ }^{[\mathrm{Ser}] \mathrm{Sec}}$ catalyzed by SLA, the biosynthesis of $\mathrm{Sec}$ on $\mathrm{tRNA}^{[\mathrm{Ser}] \mathrm{Sec}}$ would be complete and the Sec moiety then poised for insertion into the nascent selenopeptide (see Chapter 8). If this hypothesis is correct, it may be anticipated that the mechanism of Sec is synthesized on the tRNA will be resolved in the near future.

\section{Occurrence and evolution of Sec tRNA ${ }^{[S e r] S e c}$ and its insertion machinery} In 1989, the synthesis of Sec on its tRNA was reported simultaneously in bacteria [27] and mammalian cells [28]. These observations unequivocally demonstrated that $\mathrm{Sec}$ was the $21^{\text {st }}$ amino acid in the genetic code. Even though earlier studies had suggested that Sec was the $21^{\text {st }}$ amino acid [2931], when it was recognized that Sec biosynthesis occurred on its tRNA, the possibility that an intermediate, e.g., phosphoserine [20], might first be incorporated as the $21^{\text {st }}$ amino acid and then changed posttranslationally to $\mathrm{Sec}$ had to be ruled out (see discussion in [28]).

Evidence was subsequently provided that the Sec tRNA ${ }^{[\operatorname{Ser}] \operatorname{Sec}}$ gene (trsp) was universal in the animal kingdom [32] and trsp was found in numerous species of prokaryotes [33]. The occurrence of selenoproteins and the Sec protein insertion machinery was subsequently reported in archaea (see [34] and references therein), but only recently were this machinery [35] and Sec $\mathrm{tRNA}^{[\mathrm{Ser}] \mathrm{Sec}}$ [36-38] observed in eukaryotes outside the animal kingdom. Initially, the Sec incorporation machinery and at least 10 selenoproteins [35] were found in Chlamydomonas, a green alga and a member of the plant kingdom.

Since Sec tRNA ${ }^{[\mathrm{Ser}] \mathrm{Sec}}$ is a convenient marker for identifying the presence of the Sec protein insertion machinery in an organism, attention was focused on a means of demonstrating the occurrence of this nucleic acid in different eukaryotes. Initially, we devised a relatively simple procedure for partially purifying and then sequencing Sec tRNA ${ }^{[\text {Ser]Sec }}$ by reverse transcription (RT)PCR and sequenced the Sec tRNA from Chlamydomonas [36]. A computational Sec tRNA genomic analysis program for detecting trsp in partially or completely sequenced genomes was also developed (A.V. Lobanov, G. V. Kryukov and V.N. Gladyshev, unpublished data). The latter procedure in combination with isolating and sequencing the gene product by RT-PCR provided an easy and direct method for assessing whether organisms encode the machinery for incorporating $\mathrm{Sec}$ into protein. Sec $\mathrm{tRNA}^{[\mathrm{Ser}] \mathrm{Sec}}$ was identified in two model organisms, Dictyostelium discoideum and Tetrahymena thermophila [37]. The sole termination codon is T. thermophila is UGA (see [37] and references therein) and the demonstration that this organism also encodes Sec tRNA suggests that its only stop codon has a shared function. It is therefore important to note that $T$. thermophila does indeed utilize its Sec tRNA for making selenoproteins as 
its genome encodes selenoprotein genes (A.V. Lobanov and V.N. Gladyshev, unpublished data). trsp was also recently identified in various species of Plasmodium $[38,39]$ and in Toxoplasma gondii [38].

Sec tRNAs are the longest tRNAs known in either eukaryotes, archaea or prokaryotes. Prokaryotes are the longest found tRNAs thus far with some exceeding 100 bases in length [34]. All known animal Sec tRNAs ${ }^{[\mathrm{Ser}] \mathrm{Sec}}$ are 90 bases in length as are those from Chlamydomonas [36] and Tetrahymena [37]. trsp in Toxoplasma gondii is 87 bases long [38] which indicates its gene product is 90 bases in length as the CCA terminus is added posttranslationally in all tRNAs. Dictyostelium Sec tRNA is 91 nucleotides [37] and those from various species of Plasmodium are 93 nucleotides $[38,39]$. The extra base in Dictyostelium Sec tRNA ${ }^{[\mathrm{Ser}] \mathrm{Sec}}$ occurs in the Dstem, while the extra three bases in Plasmodium occur in the long extra arm. The clover leaf model of mammalian $\mathrm{Sec} t \mathrm{RNA}^{[\mathrm{Ser}] \mathrm{Sec}}$ and that of Dictyostelium are shown in Figure 1.

A

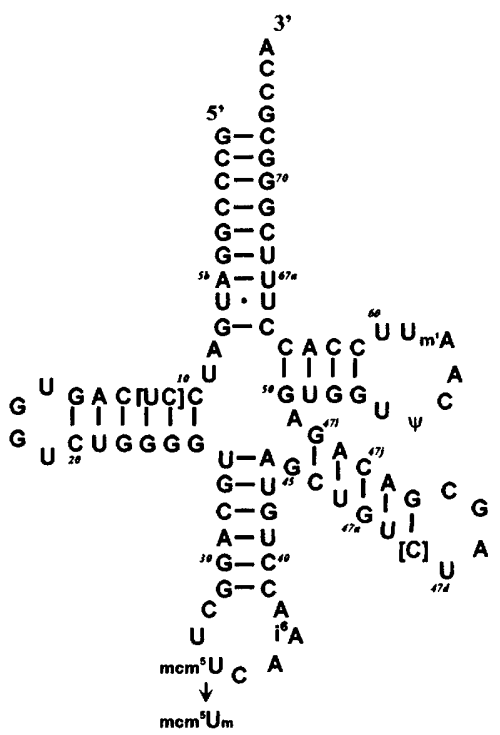

Bovine liver Sec tRNA ${ }^{[\text {Ser]Sec }}$
B

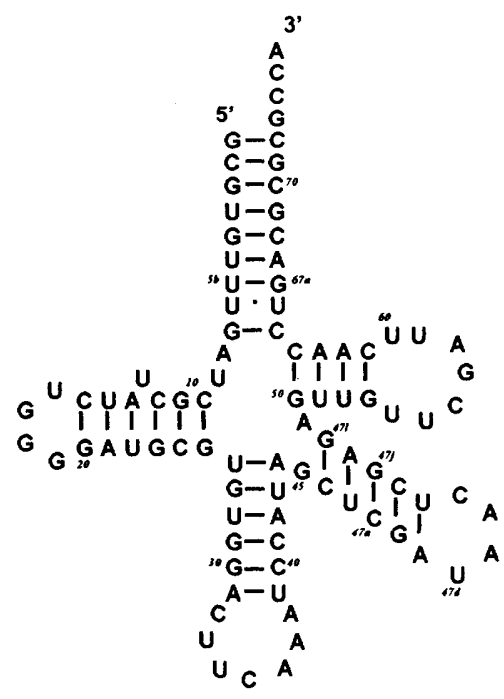

Dictyostelium discoideum Sec tRNA ${ }^{[\mathrm{Ser}] \mathrm{Sec}}$

Figure 1. Cloverleaf model of mammalian (A) and Dictyostelium (B) Sec tRNA ${ }^{[\mathrm{Ser}] \mathrm{Sec}}$. The secondary structure of the tRNA is shown in a $9 / 4$ based paired form (i.e., 9 base pairs in the acceptor stem and 4 base pairs in the T-stem). 
It is amazing that so much energy has been invested in developing a highly sophisticated system during evolution for the insertion of single amino acid, $\mathrm{Sec}$, into protein. Most of the known functions of $\mathrm{Sec}$ in protein are involved in redox reactions and thus the driving force for evolving the Sec protein incorporation machinery most likely was to utilize the unique chemical properties of the selenium atom in Sec. Under reducing environment of the cell, Sec is ionized as its $\mathrm{pKa}(\sim 5.5)$ is below physiological $\mathrm{pH}$ and it is a better participant in certain redox reactions than Cys. The pKa of Cys is 8.3, therefore, many cysteines are protonated under physiological conditions.

The dependence of different organisms on selenoproteins for survival varies widely within the three life kingdoms, eubacteria, archaea and eukaryotes. Some organisms, such as yeasts and higher plants, do not utilize selenoproteins at all, while others, such as higher vertebrates, are dependent on selenoproteins for their survival (see [3,34] and references therein). Other organisms, such as many prokaryotes, encode the $\mathrm{Sec}$ protein insertion machinery, but its occurrence often is not essential to their survival, although there must be some selective advantage for them to maintain this machinery. These observations raise important unresolved questions in selenium biology. For example, why, once such a sophisticated system evolved for utilizing the unique properties of selenium, don't all organisms take advantage of selenoproteins in cellular metabolism, or alternatively, why have some organisms lost the ability to make selenoproteins?

Although there is likely no single solution to this question, a better understanding of those organisms that do and do not make selenoproteins will most certainly shed light on this enigma. As Sec tRNAs provide a readily identifiable marker for the presence of the Sec protein insertion machinery, and the computational and sequencing techniques described above are so readily applicable to identifying Sec tRNAs, focusing on the occurrence of trsp and/or Sec tRNA will provide a means of assessing how widespread the use of $\mathrm{Sec}$ is in nature.

\section{Acknowledgements}

This work was supported by the Intramural Research Program of the National Institutes of Health, National Cancer Institute, Center for Cancer Research.

\section{References}

1. RM Tujebajeva, PR Copeland, XM Xu, BA Carlson, JW Harney, DM Driscoll, DL Hatfield, MJ Berry 2000 EMBO Rep 1:158

2. D Fagegaltier, N Hubert, K Yamada, T Mizutani, P Carbon, A Krol 2000 EMBO J 19:4796

3. DL Hatfield, BA Carlson, XM Xu, H Mix, VN Gladyshev 2006 Prog Nucl Acids Res Mol Biol (In Press)

4. DL Hatfield, VN Gladyshev 2002 Mol Cell Biol 22:3565

5. LK Kim, T Matsufuji, S Matsufuji, BA Carlson, SS Kim, DL Hatfield, BJ Lee 2000 RNA 6:1306 
6. AM Diamond, IS Choi, PF Crain, T Hashizume, SC Pomerantz, R Cruz, CJ Steer, KE Hill, RF Burk, JA McCloskey, DL Hatfield $1993 \mathrm{~J}$ Biol Chem 268:14215

7. BA Carlson, XM Xu, VN Gladyshev, DL Hatfield 2005 J Biol Chem 280:5542

8. BA Carlson, XM Xu, VN Gladyshev, DL Hatfield 2005 In Grosjean (Ed.): Fine-Tuning of RNA Functions by Modification and Editing. Topics in Current Genetics Vol. 12. pp 431-438

9. SL Weiss, RA Sunde 1998 RNA 4:816

10. PM Moriarty, CC Reddy, LE Maquat 1998 Mol Cell Biol 18:2932

11. SC Low, MJ Berry 1996 Trends Biochem Sci 21:203

12. F Ding, PJ Grabowski 1999 RNA 5:1561

13. XM Xu, H Mix, BA Carlson, PJ Grabowski, VN Gladyshev, MJ Berry, DL Hatfield 2005 J Biol Chem 280:41568

14. C Gelpi, EJ Sontheimer, JL Rodriguez-Sanchez 1992 Proc Natl Acad Sci USA 89:9739

15. A Small-Howard, N Morozova, Z Stoytcheval, EP Forryl, JB Mansell, JW Harney, BA Carlson, XM Xu, DL Hatfield, MJ Berry $2005 \mathrm{Mol}$ Cell Biol (In Press)

16. DL Tumbula, HD Becker, WZ Chang, D Soll 2000 Nature 407:106

17. A Sauerwald, W Zhu, TA Major, H Roy, S Palioura, D Jahn, WB Whitman, JR Yates, M Ibba, D Soll 2005 Science 307:1969

18. PH Maenpaa, MR Bernfield 1970 Proc Natl Acad Sci US A 67:688

19. D Hatfield, FH Portugal 1970 Proc Natl Acad Sci U S A 67:1200

20. D Hatfield, A Diamond, B Dudock 1982 Proc Natl Acad Sci U S A 79:6215

21. BA Carlson, XM Xu, GV Kryukov, M Rao, MJ Berry, VN Gladyshev, DL Hatfield 2004 Proc Natl Acad Sci US A 101:12848

22. AM Diamond 2004 Proc Natl Acad Sci U S A 101:13395

23. RS Glass, WP Singh, W Jung, Z Veres, TD Scholz, TC Stadtman 1993 Biochemistry 32:12555

24. MJ Guimaraes, D Peterson, A Vicari, BG Cocks, NG Copeland, DJ Gilbert, NA Jenkins, DA Ferrick, RA Kastelein, JF Bazan, A Zlotnik 1996 Proc Natl Acad Sci U S A 93:15086

25. IY Kim, TC Stadtman 1995 Proc Natl Acad Sci U S A 92:7710

26. SC Low, JW Harney, MJ Berry 1995 J Biol Chem 270:21659

27. W Leinfelder, TC Stadtman, A Bock 1989 J Biol Chem 264:9720

28. BJ Lee, PJ Worland, JN Davis, TC Stadtman, DL Hatfield 1989 J Biol Chem 264:9724

29. I Chambers, J Frampton, P Goldfarb, N Affara, W McBain, PR Harrison 1986 EMBO J 5:1221

30. F Zinoni, A Birkmann, TC Stadtman, A Bock 1986 Proc Natl Acad Sci U S A 83:4650

31. W Leinfelder, E Zehelein, M Mandrandberthelot, A Bock 1988 Nature 331:723

32. BJ Lee, M Rajagopalan, YS Kim, KH You, KB Jacobson, D Hatfield $1990 \mathrm{Mol}$ Cell Biol 10:1940

33. J Heider, A Bock 1993 Adv Microb Physiol 35:71

34. GV Kryukov, S Castellano, SV Novoselov, AV Lobanov, O Zehtab, R Guigo, VN Gladyshev 2003 Science 300:1439

35. SV Novoselov, M Rao, NV Onoshko, H Zhi, GV Kryukov, Y Xiang, DP Weeks, DL Hatfield, VN Gladyshev 2002 EMBO J 21:3681

36. M Rao, BA Carlson, SV Novoselov, DP Weeks, VN Gladyshev, DL Hatfield 2003 RNA 9:923

37. RK Shrimali, AV Lobanov, XM Xu, M Rao, BA Carlson, DC Mahadeo, CA Parent, VN Gladyshev DL Hatfield 2005 Biochem Biophys Res Commun 329:147

38. AV Lobanov, C Delgado, S Rahlfs, SV Novoselov, GV Kryukov, S Gromer, DL Hatfield, K Becker, VN Gladyshev 2005 Nucl Acids Res 34:496.

39. T Mourier, A Pain, B Barrell, S Griffiths-Jones 2005 RNA 11:119 